\title{
EL LENGUAJE ClasicizanTE DE GIOVANNI PASCOLI. UN PROBLEMA DE TRADUCCIÓN
}

Mariapia Lamberti

En 1904, cuando aparecieron los Poemi Conviviali, Giovanni Pascoli había obtenido ya su tercera cátedra universitaria en Filología clásica. Nacido en 1855, había ingresado en 1895 en la Universidad de Bolonia como docente encargado de Gramática latina y griega; dos años después había ocupado la cátedra de Literatura latina en la Universidad de Mesina, y desde 1903 era titular de la de Gramática griega y latina en la Universidad de Pisa, cátedra que debería abandonar en 1906 para ocupar la prestigiada de Literatura italiana en el Ateneo de Bolonia, que había pertenecido a Giosué Carducci. Su justificado prestigio de sólido humanista tenía, sin embargo, el singular matiz de la entonación poética, ya que Pascoli, más que un estudioso y un docto en filología, era un amante nostálgico del mundo clásico, en el cual "vivía" recreándolo en sí mismo, y expresándolo en las últimas perfectas poesías latinas que ha dado al mundo la saturnia tellus. Efectivamente, se había hecho acreedor, en muchas ocasiones, del máximo galardón otorgado anualmente por la academia Hoefftiana de Amsterdam en un concurso internacional de poesía latina (en el transcurso de su vida obtuvo 13 veces la medalla de oro y otras tantas la mención de honor). Sin embargo, hay que mencionar que el revivir poético de la antiguedad clásica en Pascoli se condiciona a su vez por su calidad de gramático, ya que no involucra aspectos esenciales, o sea la cosmovisión pagana y viril, combativa y sensual, del mundo grecolatino, sino aspectos formales - verbales-, una manera de expresarse que el poeta adopta para su mundo íntimo atento a las humiles myricae y a los aspectos dolorosos de la vida sufridos en formas obsesivas y un poco -o un mucho- plañideras, con una morbidez matizada de cristianismo populista y decadente melancolía.

La poesía de Pascoli en lengua italiana, de hecho, más que por su temática repetitiva (el mundo de la naturaleza observado en sus aspectos cotidianos y humildes; el dolor humano y la injusticia del mundo, entendidos en sus manifestaciones más personales, más ligadas a su experiencia individual; los detalles más patéticos y un tanto cursis de la infancia; la pobreza; la muerte), 
representa un hito insoslayable del punto de vista de la renovación formal, que inicia aquel proceso de transformación de la poesía italiana que culminaría con la poesía pura de Ungaretti y Montale. La reforma (o más bien la búsqueda) formal de Pascoli comprende aspectos tan disímbolos como la introducción de onomatopeyas; el empleo de nomenclaturas vastísimas, minuciosas, y muchas veces dialectales, relativas a los objetos y fenómenos de la naturaleza; la disolución de la sintaxis tradicional en esquemas más libres y rarefactos; y el uso de formas métricas grecolatinas adaptadas al sistema acentual y rimado de la lengua italiana (en su obra Odi e Inni se reconocen estrofas sáficas, alcaicas, asclepiadeas mayor y menor, etcétera: toda la gama métrica horaciana). Se acopla así la lucha en contra del clasicismo asfixiante que había aquejado a la poesía italiana durante siglos -involucrando todos los aspectos: temático, retórico y verbal-con un intento de reintroducir las variedades métricas de la lengua madre en pos de una libertad nueva también en el ámbito rítmico.

Esta búsqueda de novedad realizada a través de la adopción de la métrica clásica grecolatina, es el único aspecto en el cual Pascoli no fue precursor, sino epígono: antes de él otros habían hecho el intento, y recordaremos únicamente a Gabriello Chiabrera, en el siglo XVII, y a Giosué Carducci, antecesor y maestro del Pascoli.

Sin embargo, el lado más sorprendente de la obra de este poeta, desconcertante por sus subidas repéntinas a los niveles más puros de poesía y sus caídas constantes en la más desalentadora dulzoneria,' lo representan los Poemi Conviviali, extrañamente poco conocidos y estudiados en el sistema escolar italiano que ha dado la preferencia durante decenios a los lacrimosos Canti di Castelvecchio y Myricae.

En los primeros de estos poemas (llamados conviviali por haber aparecido primeramente en Il Convito, publicación literaria de Adolfo de Bosis) hay una serie de narraciones breves - de tono no épico, sino idílico - de ambiente griego, pero de una grecidad literaria: los protagonizan Homero, Hesíodo, Solón, Safo, Ulises, Anticlo, Aquiles. El motivo inspirador, dominante, es la nostalgia ardiente por aquel mundo, perdido en todos sus aspectos menos el de su poderosa expresión verbal; una nostalgia que se manifiesta en la recreación más perfecta del lenguaje griego que se haya hecho en lengua italiana. La consabida temática pascoliana pasa a segundo término, se diluye en este mundo de imágenes evanescentes perseguidas con el desesperado afán con que Orfeo intentó rescatar la sombra de su amada. Sorprende en este poeta discontinuo una inspiración tan pareja, y un tan constante diapasón de perfección expresiva.

Pero lo que más extraña en estos poemas dedicados al mundo de la poesía helénica, es la ausencia casi total de una métrica modelada sobre los modos griegos. El autor usa casi exclusivamente el tradicional verso italiano -el endecasílabo jugando con sus posibilidades rítmicas para recrear la impresión musical de la poesía inspiradora. Tal impresión se refuerza por efecto de una morfología rica en

1 Véase a este respecto el ensayo siempre actual de Benedetto Croce en La letteratura della Nuova Italia, Vol. IV, Laterza, Bari, 1915, pp. 71-127. 
construcciones a la griega o a la latina; Pascoli hilvana su discurso a base de epítetos exornativos, fórmulas repetidas, descripciones y comparaciones ornamentales; y emplea vocablos construidos al modo griego (fusión de sustantivo con adjetivo) o transcritos directamente del griego (esto último sólo en caso de objetos o funciones pertenecientes únicamente al mundo clásico).

Traducir estos poemas representa un reto múltiple, ya que una traducción que transmitiera únicamente el contenido narrativo e ideológico traicionaría la inspiración fundamental del poeta, que es formal, ya que a través de las formas se expresa su contenido básico: su estrujante nostalgia.

El primero de los dos poemas, cuya traducción se presenta aquí, "Solón" -el que abre el volumen y tal vez el más conocido de todos - se desarrolla en dos modos (y quisiera dar a este término su valor musical griego): uno es el narrativo (vv. 1-4, 61-63 y 84-85), y en él el poeta imita el ritmo de la poesía épica (hexámetros), no sólo a través del uso de los acent os y de algunas sabias estridencias fonéticas, sino también abundando en encabalgamientos que causan una impresión de mayor amplitud del verso, lo que aumenta el efecto discursivo. El otro modo es el lírico, y lo constituyen dos canciones (vv. 41-60 y 64-83) en estrofas sáficas mayores. Estas también se estructuran en endecasílabos (tres por cada estrofa) más un adonio, o sea un pentasílabo casi siempre con un acento en la primera sílaba. Pero estos endecasílabos tienen una musicalidad cantante que los distingue de los anteriores narrativos, y presentan una casi constante coincidencia entre la medida sintáctica y la del verso. El efecto musical se acrecienta por el uso de las rimas alternas (ABAb). En esta traducción (que supongo la primera en lengua española) me he esforzado en mantener esta dualidad ritmica, y reproducir, en la medida de lo posible, el lenguaje grecizante que, perfectamente asimilable al italiano, puede resultar insólito en español.

Quiero adelantar que es mi opinión, respecto al arte de traducir, que es obligación del traductor, ante todo, respetar al máximo el sentido del texto, o sea sus palabras: el "arte" reside justamente en lograr al límite de lo posible todos los demás efectos: ritmo, armonía, rimas, construcciones. Traducir no es, en mi opinión, recrear, sino únicamente transmitir unos valores culturales; es una labor de divulgación, no de creación. Y aún así el traduttore será traditore, pero por lo menos no será asesino. Cambiar un texto persiguiendo una rima o un número exacto de sílabas puede resultar una arbitrariedad imperd onable. La traducción del italiano al español, específicamente, se puede fácilmente creer que sea sencilla debido a la engañosa similitud fonética de los dos idiomas. Pero ¡ay de este plural en -s que alarga, inmisericorde, los versos italianos construid os a base de sinalefas! ¡Ay del pobre cuore que se transforma en el trisilábico y cacofónico "corazón"! Sin embargo, una versión que respete la medida de los endecasílabos (y de cualquier otra forma métrica cuya musicalidad sea importante para el efecto poético) es casi siempre posible con un poco de esfuerzo y un mucho de lima.

En esta traducción, como ya dije, he tratado de conservar el ritmo de los versos, que tiene una importancia, por así decirlo, connotativa: pero no he luchado más que lo necesario para mantener las rimas de las estrofas sáficas -que se encuentran 
por lo tanto sólo en los casos en que la homofonía de los dos idiomas lo permita.

Para respetar el ritmo endecasilábico alteré la posición del verbo "posee" (en italiano ha) del v. 17 al v. 18, creando un encabalgamiento muy coherente con el estilo de este poema, como se analizó arriba. Alteré ta mbién la estructura sintáctica de los vv. 40 y 63 (iguales en su formulismo homérico) eliminando la conjunción entre las dos oraciones y sustituyéndola con un punto y coma: fue la arbitrariedad más grande que me permití, pero no evitó que los versos fueran hipermétricos. ${ }^{2}$

En las canciones sáficas, he transformado el manzano (en italiano melo) que tiembla al plenilunio en el v. 41 en un "piesco" por motivo de sílabas: puesto que los dos árboles frutales evocan la idea de la nube de flores que bien puede, en ambos casos, tener matices plateados a la luz de la luna, a pesar de la ligera diferencia de coloraciọn de los pétalos.

No pude mantener el efecto onomatopéyico del v. 44 (sibila il vento) y 45 (strepita tra le forre) porque no hay en español un verbo tan ruidoso como strepitare; ni "silbar" resulta tan descriptivo como sibilare con sus dos /i/ repetidas. La mayor riqueza del italiano en terminología relativa a los sonidos es problema bien conocido por los traductores. Opté entonces respectivamente por "ulular" y "aullar" que me permitieron al mismo tiempo respetar la medida silábica de los versos y crear otro efecto de armonía imitativa a través de la aliteración de las $|\mathbf{u}-\mathbf{a}|$.

En la segunda canción sáfica el v. 72 resultó hipermétrico; pero no quise eliminar el término onomatopéyico "tintineo" (en italiano tintinno) tan pascoliano.

También eliminé (y fue la segunda arbitrariedad) el qui temporal (en latín: hic = "en este lugar" o "en este momento") del v. 85.

En el nivel verbal he mantenido las estructuras sintácticas y los giros de construcción del original: a pesar de que el italiano es una lengua hiperbática, las construcciones inversas de este poema suenan, por arte del poeta, tan latinas (o griegas) como quise que sonaran al lector de lengua castellana.

El v. 17 presenta en italiano una formación lexical insólita, moldeada sobre las griegas: solidunghi. La reproduje en español estructurando el término según las reglas de este idioma: anteponiendo el sustantivo al adjetivo, al revés de lo que se hace en italiano: "uñisólidos".

También respeté el latinismo del v. 64: togli, que reproduce el latín tolle (del cual deriva), usado a menudo en eate sentido de "dejar, cesar alguna acción", sobre todo, como en este caso, al imperativo: una especie de "ya basta". Preferí dejar en español un algo insólito "quita el llanto" (la diferencia fonética no remite tan claramente al tolle inspirador), en lugar de un "basta de llanto" banalizador e infiel; infiel porque en la intención del poeta la expresión debe resultar clara únicamente al lector que sabe el latín y la "lee" en latín.

2 La solución hubiera sido tal vez traducir fremebonde por "vibrantes": pero me pareció rebajar la infagen, ya que "vibrantes" significa "que están vibrando", acción material y definitiva en el tiempo, mientras que fremebonde significa "dispuestas y casi ansiosas al punto de temblar". 
Transcribí en grafía española los términos sacados directamente del griego y transcritos a la italiana en el texto original, reproduciendo así la labor del poeta; cada uno tiene su explicación en nota.

El segundo poema traducido pertenece a otro grupo de composiciones de los Conviviali, que se inspiran libremente en figuras ya no literarias sino históricas del mundo clásico y bárbaro, vistas a través de sus aspectos más sugestivos o legendarios: Alejandro, Tiberio, Gog y Magog. En estos poemas el aspecto formal es interesante y sorpresivo por la gran libertad de inspiración, ya que el poeta se desliga de la imitación del lenguaje y de los ritmos de la gran poesía clásica. En "Aléxandros" por ejemplo, el segundo poema aquí presentado, la inspiración es típicamente pascoliana: partiendo de la famosa leyenda del llanto de Alejandro al llegar a los confines del mundo -a la imposibilidad de extender más allá los límites del sueño y del deseo-, el poeta construye un canto de estrujante anhelo por lo irreal, lo no vivido, el sueño, como única fuente de infinitas posibilidades, en contraste con la infinita decepción de lo real, lo realizado. La musicalidad en este poema es importantísima, pues sobre ella se apoya toda la sensación onírica que oscila entre la añoranza de lo ya vivido y el deseo de lo no vivido.

El poema se articula en 6 estrofas de tres tercetos dantescos cada una, más un verso que cierra el juego de las rimas (ABABCBCDCD); por lo tanto la musicalidad es muy evidente. Sin embargo, no es solamente la presencia de las rimas la que produce este tono cantado: los versos tienen, todos, una cadencia sugestiva que llega en algunos casos a una verdadera armonía imitativa: baste observar el v. 36 y el v. 50. Abundan los paralelismos, mientras los encabalgamientos están casi ausentes. Los lazos con lo clásico se limitan al uso de una nomenclatura específica, reducida de otro lado casi únicamente a la primera estrofa y a la acentuación grecizante de los nombres.

En mi versión he considerado este aspecto musical de importancia primaria: por eso me he comportado con una libertad mayor que en el poema precedente. Por ejemplo, el v. 20 es, sencillamente, uno de los versos más bellos de toda la poesía italiana. Traicionar el profundísimo concepto resultaba una acción sacrilega: pero igualmente imperdonable hubiera sido alterar la estructura métrica del verso, su misma acentuación. Encontrar una solución válida resultó ser una empresa casi desesperada, y la estupenda perfección del verso original no encontró una correspondencia digna en castellano: pero la estructura total del poema resultó salvada.

No consideré importante el problema de las rimas, limitándome a mantener una cierta armonía en las terminaciones de los versos. En un caso me fue posible mantener una rima operando una inversión de dos versos (el v. 51 y 52) que no alteró mínimamente el sentido. Pero en otros casos preferí modificar, en parte, algunas expresiones con tal de mantener este efecto de balada, la cadencia como de canción de cuna que acompaña a este poema del sueño y la nostalgia. He sacrificado al endecasílabo la complejidad morfosintáctica de los vv. 15-16, que presentan además el único latinismo del poema: el verbo invidiare en el sentido de "sustraer, esconder". 
También he sacrificado, por razones métricas, la perfección del paralelismo de los vv. 42-43 (en el segundo verso no traduje la palabra "ojo"), y de los vv. 58-59 que inician ambos con el verbo ascolta; recurrí a la pareja "escucha-oye" cuya diferencia de sentido no es determinante en este caso.

Más grave fue la supresión (en el v. 53 de mi traducción, 52 del original), del adjetivo dolce, referido al Ausente para el que hilan Olympiás y las otras hermanas; y se pierde con ello una connotación sicológica de los personajes femeninos, que del héroe lejano ven únicamente la dulzura de los lazos afectivos familiares: y sabemos que el contraste entre lo masculino -impulso de conquista que acaba en la decepción suprema de la finitud de lo Real - y lo femenino - limitación en el nivel de lo cotidiano que se abre a las ilimitadas posibilidades del Sueño-es el tema fundamental del poema.

Sin embargo, consideré que en este poema el aspecto de la cadencia rítmica y de los efectos fonéticos tenía una importancia primordial, y un verso hipermétrico hubiera estropeado irremediablemente todo el poema. Los tres versos hipermétricos que quedaron en la traducción de "Solón" se integran en un ritmo que trata de imitar la variabilidad silábica de los versos cuantitativos de laș dos lenguas clásicas, y su estridencia no desentona, como lo haría aquí. En las varias posibilidades de traducción que cada verso ofrecía (a veces numerosas) opté por las que reprodujeran la misma colocación de acentes del original.

En estos poemas de Pascoli, el respeto a la colocación de un acento puede ser más importante que el respeto a la significación de un término; así como la conservación de un término desacostumbrado puede ser más importante que la comprensión inmediata y "fácil" del lector.

Esta sensibilidad a las prioridades poéticas es parte, a mi ver, de las cualidades necesarias para ser un buen traductor de poesía, pues la regla básica del traducir es y debe ser el sometimiento al texto.

\section{TRADUCCIÓN}

\section{Solón}

Triste el convite sin el canto, como templo sin el votivo oro de dones; pues esto es bello: atender al cantor que en la voz tiene el eco del Misterio.

5 ¡Oh! Nada, yo digo, es bello más que oír a un cantor bueno, plácidos, sentados unos con otros, a las mesas llenas de rubios panes y humeantes carnes, mientras del cráteŕ el doncel extrae 
10 vino, y lo lleva a escancia en las copas; y decir mientras graciosos dichos, cuando eleva el sagrado himno la cítara; o del quejoso auletés ${ }^{1}$ que llora gozar, pues en tu alma se transforma

15 el dolor suyo en tu felicidad.

Solón, un día dijiste tú: dichoso quien ama, y uñisólidos caballos posee, perros de presa, un huésped lejos. Mas ni el lejano huésped te complace

20 hoy, ni, ya viejo, perros o caballos de sólida uña, ni el amor, o sabio. Te complace la copa ahora: alabas más viejo el vino y novedoso el canto. $Y$ al Pireo novedosas, con la calma

25 primera y los chubascos, dos canciones ultramarinas llegaron. Las lleva una mujer de Eresso. "Abre -contestaPhoco, a la golondrina, abre la puerta. Eran las Anthesterias: ${ }^{2}$ se abría

30 el odre ahumado, y se cataba el vino. Entró con la luz de la primavera y el aliento salobre del Egeo la cantatriz. Ella sabía dos cantos: uno, de amor; el otro era de muerte.

35 Absorta entro: y Phoco le ofrecía un escabello ornado de áureas placas y una copa. Sentóse sosteniendo la resonante pectis: ${ }^{3}$ retorció callada, en sus cólabos 4 las cuerdas;

40 tentó las cuerdas estremecidas; dijo:

Brilla en el plenilunio el huerto: el piesco tiembla apenas con un temblor de plata... En los lejanos montes color del cielo ulula el viento. 
45 Muge el viento, aúlla en los barrancos se avienta en los encinos... el mío parece sólo un temblor, pero es amor, y corre ¡cansa los miembros!

Lejos está de mis rizos cabellos

50 cuanto el sol; sí, pero me llega al alma como el sol: bello, pero bello como sol cuando muere.

¡Desvanecerme! y otro no quiero: quiero hacerme claridad que de él se efunda;

55 escollo extremo de la gran luz, escollo de la gran onda,

dulce es en ti descender donde hay la paz: desciende el sol en el infinito mar; tiembla y desciende la claridad que sigue crepuscular.

¡La Muerte es ésta! El viejo exclamó. - Este contestó ella, -es, huésped, el Amor.

Tentó las cuerdas estremecidas; dijo:

Quita el llanto ¡Es culpa! Del poeta

65 en la casa estas tú. ¿Quién dirá que fui? Llora al muerto atleta: su belleza muere con él.

Muere el valor del héroe que el carro gritando avienta en las adversas filas; muere el pecho, sí, de Rhodopi, el ojo del timonel;

mas el canto no muere, que en el tintineo de la pectis abre el candor de su ala; y el poeta, mientras no muera el himno vive, inmortal, pues el himno (den los rosados dedos paz al peplo, a nos no conviene el luto) es nuestra fuerza y belleza, la vida, el alma, itodo! 
80 Y aquel que quiera ver, toque estas cuerdas, cante mi canto: entonces los ojos mirarán, toda de rosas Safo la bella.

Éste era el canto de la muerte: y el viejo

85 Solón dijo: que yo lo aprenda, y muera.

Solon

Triste il convito senza canto, come tempio senza votivo oro di doni; ché questo è bello: attendere al cantore che nella voce ha l'eco dell'Ignoto.

$5 \mathrm{Oh}$ ! nulla, io dico, è bello più, che udire un buon cantore, placidi, seduti l'un presso l'altro, avanti mense piene di pani biondi e di fumanti carni, mentre il fanciullo dal cratere attinge

10 vino, e lo porta e versa nelle coppe; e dire in tanto graziosi detti, mentre la cetra inalza il suo sacro inno; o dell'auleta querulo, che piange, godere, poi che ti si muta in cuore

15 il suo dolore in tua felicitã.

-Solon, dicesti un giorno tu: Beato chi ama, chi cavalli ha solidunghi, cani da preda, un ospite lontano. Ora te né lontano ospite giova

20 né, già vecchio, i bei cani né cavalli di solid'unghia, né l'amore, o savio. Te la coppa ora giova: ora tu lodi più vecchio il vino e più novello il canto. E novelle al Pireo, con la bonaccia

25 prima e co' primi stormi, due canzoni oltremarine giunsero. Le reca una donna d'Eresso - Apri: rispose; alla rondine, o Phoco, apri la porta. Erano le Anthesterie: s'apriva

30 il fumeo doglio e si saggiava il vino.

Entrò, col lume della primavera e con l'alito salso dell'Egeo, 
la cantatrice. Ella sapea due canti:

l'uno, d'amore, l'altro era di morte.

35 Entrỏ pensosa; e Phoco le porgeva uno sgabello d'auree borchie ornato ed una coppa. Ella sedé, reggendo la risonante pèctide; ne strinse tacita intorno ai còllabi le corde;

40 tentò le corde fremebonde, e disse:

Splende al plenilunio l'orto; il melo trema appena d'un tremolio d'argento...

Nei lontani monti color di cielo sibila il vento.

45 Mugghia il vento, strepita tra le forre, su le quercie gettasi... Il mio non sembra che un tremore, ma è l'amore, e corre, spossa le membra!

M'è lontano dalle ricciute chiome,

50 quanto il sole; si, ma mi giunge al cuore, come il sole: bello, ma bello come sole che muore.

Dileguare! e altro non voglio: voglio farmi chiarita che da lui si effonda.

55 Scoglio estremo della gran luce, scoglio su la grande onda,

dolce è da te scendere dove è pace: scende il sole nellinfinito mare; trema e scende la chiaritå seguace crepuscolare.

La Morte è questa! il vecchio esclamǒ. Questo, ella rispose, è, ospite, l'Amore.

Tentò le corde fremebonde, e disse:

Togli il pianto. E colpa! Sei del poeta

65 nella casa, tu. Chi dirà che fui?

Piangi il morto atleta: beltà d'atleta muore con lui.

Muore la virtù dell'eroe che il cocchio spinge urlando tra le nemiche schiere; 
70 muore il seno, si, di Rhodòpi, l'occhio del timoniere;

ma non muore il canto che tra il tintinno della pectide apre il candor dell'ale. E il poeta fin che non muoia l'inno, vive, immortale, poi che l'inno (diano le rosee dita pace al peplo, a noi non s'addice il lutto) É la nostra forza e beltà, la vita,

l'anima, tutto!

80 E chi voglia me rivedere, tocchi queste corde, canti un mio canto: in quella, tutta rose rimireranno gli occhi

Saffo la bella.

Questo era il canto della Morte; $\mathrm{e}$ il vecchio 85 Solon qui disse: Ch'io l'impari, e muoia.

Alexandros

I

Llegamos: es el fin. Sagrado heraldo, jentona!

Otra tierra ya no, sino, en el aire, la que en el medio del escudo os brilla,

¡oh Petzeterios!! Errante y solitaria tierra, inviolada. De la extrema orilla miráis allá, Misthóforos de Caria, ${ }^{2}$

el último río, Océano, sin olas.

Vos que vinisteis de Haemo y de Carmelo, la tierra, veis, se esfuma y desvanece

dentro la noche fúlgida del cielo. 


\section{II}

¡Torrentes que crucé! Vos la foresta inmóvil en la clara agua lleváis, lleváis el murmurar sombrío, que resta. ¡Montañas que pasé! Mas, ya pasadas, tan grande no aparece, desde arriba, el espacio que habíais ocultado.

Azules como el cielo, como el mar, ¡oh montes! ¡ríos! Era mejor consejo quedarse, no mirar lejos, isoñar!

Sueño es sombra infinita de lo Real.

\section{III}

¡Oh! ¡ Más feliz yo cuanto más camino tenía delante; cuantas más batallas, cuantas más dudas, cuanto más destino!

¡En Iso! Cuando flameaba al viento nocturno el campo, con sus mil escuadras, carros oscuros, hatos infinitos.

¡En Pella! Cuando en prolongadas tardes ¡Oh Cabeza-de-toro ${ }^{3}$ mío!, seguíamos el sol; el sol que entre las selvas negras más lejos siempre, ardía como un tesoro.

\section{IV}

¡Hijo de Amynta!4 Yo no sabía de metas cuando partí. Un nomos ${ }^{5}$ por las aras el auletés ${ }^{6}$ Timótheos entonaba:

${ }^{3}$ El nombre de caballo de Alejandro era Bucéfalo (Bowxipahós) o sea Cabeza de toro.

4'AuuvT'as : nombre del rey de Macedonia, padre de Alejandro.

s vojos : composición musical que tenía reglas de composición muy precisas, de donde su nombre que significa "ley, regla".

6 asinpms : sonador de flauta. 
soplo potente de un fatal andar más allá de la muerte: en mí presente como en concha el murmullo de la mar.

¡Oh toque agudo, oh espiritu potente que pasas alto y gritas que te siga! Mas éste es el Final, el Mar, la Nada...

y el canto pasa, y más allá se pierde.

Y llora, así, ya que llegó anhelante:

llora del ojo negro como muerte;

llora del ojo azul como cïelo.

Pues se hace siempre (y tal es su suerte) en el negro ojo el esperar, más vano; en el azul el desear, más fuerte.

Él oye fieras vibrar a lo lejos, oye incógnitas fuerzas, incesantes, pasar de frente en el inmenso llano,

como, al trote, manadas de elefantes.

\section{VI}

Mientras, hilan sus vírgenes hermanas, en el áspero Epiro montañoso, para el Ausente la milesia lana.

En la alta noche, entre hacendosas duef̂as, tuercen el huso con sus céreos dedos; y el viento pasa, y pasan las estrellas.

Olympiás, en un sueño perdida, escucha el largo charlar de una fuente, oye en la sombra hueca e infinita

susurros de los robles sobre el monte. 


\section{Alexandros}

\section{I}

—Giungemmo: è il Fine. O sacro Araldo, squilla!

Non altra terra se non là, nell'aria,

3 quella che in mezzo del brocchier vi brilla,

o Pezetèri: errante e solitaria

terra, inaccessa. Dall'ultima sponda

6 vedete là, mistofori di Caria,

l'ultimo fiume Oceano senz'onda.

$O$ venuti dall'Haemo e dal Carmelo,

9 ecco, la terra sfuma e si profonda

10 dentro la notte fulgida del cielo.

\section{II}

Fiumane che passai! voi la foresta immota nella chiara acqua portate,

13 portate il cupo mormorio, che resta.

Montagne che varcai! dopo varcate, si grande spazio di su voi non pare,

16 che maggior prima non lo invidiate.

Azzurri, come il cielo, come il mare, o monti! o fiumi! era miglior pensiero

19 ristare, non guardare oltre, sognare:

20 il sogno è l'infinita ombra del Vero.

\section{III}

Oh! più felice, quanto più cammino m'era d'innanzi; quanto più cimenti,

23 quanto più dubbi, quanto più destino!

Ad Isso, quando divampava ai vènti notturno il campo, con le mille schiere,

26 e i carri oscuri e gl'infiniti armenti. 
A Pella! quando nelle lunghe sere inseguivamo, o mio Capo di toro,

29 il sole; il sole che tra selve nere,

30 sempre più lungi, ardea come un tesoro.

IV

Figlio d'Amynta! io non sapea di meta allor che mossi. Un nomo di tra le are

33 intonava Timotheo, l'auleta:

soffio possente d'un fatale andare, oltre la morte; e m'è nel cuor, presente

36 come in conchiglia murmure di mare.

O squillo acuto, o spirito possente, che passi in alto é gridi, che ti segua!

39 ma questo è il Fine, è l'Oceano, il Niente...

40 e il canto passa ed oltre noi dilegua. -

\section{V}

E cosi, piange, poi che giunse anelo: piange dall'occhio nero come morte;

43 piange dall'occhio azzurro come cielo.

Ché si fa sempre (tale è la sua sorte) nell'occhio nero lo sperar, più vano;

46 nell'occhio azzurro il desiar, più forte.

Egli ode belve fremere lontano, egli ode forze incognite, incessanti, 49 passargli a fronte nell'immenso piano,

50 come trotto di mandre d'elefanti.

\section{VI}

In tanto nell'Epiro aspra e montana filano le sue vergini sorelle

53 pel dolce Assente la milesia lana. 
A tarda notte, tra le industri ancelle, torcono il fuso con la ceree dita;

56 e il vento passa e passano le stelle.

Olympiàs in un sogno smarrita ascolta il lungo favellio d'un fonte,

59 ascolta nella cava ombra infinita

60 le grandi quercie bisbigliar sul monte. 